\title{
International Student Mobility Programs and Effects on Student Teachers' Perceptions and Beliefs about Education and Their Role as Future Educators
}

\author{
Rachel Richardson ${ }^{1, *}$, Jennifer Munday ${ }^{2}$ \\ ${ }^{1}$ Faculty of Science, Charles Sturt University, Albury, 2460, New South Wales, Australia \\ ${ }^{2}$ Faculty of Education, Charles Sturt University, Albury, 2460, New South Wales, Australia \\ *Corresponding Author: rachelr1360@gmail.com
}

Copyright (C 2013 Horizon Research Publishing All rights reserved.

\begin{abstract}
The aim of this study was to examine the value and benefits obtained from a semester length academic exchange for Australian early childhood teacher education students in equivalent programs in selected European sites. The data obtained from interviews conducted in this qualitative study indicate that students involved in the international mobility program experienced changes to their own sense of identity and their perception of other cultural practices and attitudes. In particular, the students' international experiences caused them to reflect deeply on matters of early childhood practice in their host and home countries and these reflections led, in some cases, to reconsiderations of their future role as practitioners. The students' reflections also offer the university sector some points to consider with respect to student mobility programs, particularly in how participants are supported in interpreting their overseas experience.
\end{abstract}

Keywords Internationalisation; Global curriculum; Student exchange; Cross-cultural understanding

\section{Introduction}

The area of internationalisation of the curriculum is a major thrust within higher education globally. The form, however, that internationalisation takes in a particular institutional context has both a historical and national basis (Adams, 2007; Altbach \& Knight, 2007; Altbach \& Tiechler, 2001, Healey, 2007; Knight, 2004). While internationalisation is now an important stated aim often embedded within University charter and planning statements, the actual manifestation of internationalisation differs widely amongst institutions both within and between nations (Altbach \& Knight, 2007; Knight, 2004). In some instances, internationalisation seems to be driven by economic considerations. And indeed, how an institution can financially benefit from selling its courses and programs to overseas students has at least some place in most institutions' consideration of the 'bottom line' in internationalisation. But internationalisation means more than this and modern interpretations include matters related to cultural and intellectual exchange, mutual enterprise, human resource development, improving instructional quality and course content, institutional reputation enhancement and so on (see Knight, 2004, for a fuller analysis; also Jones and Brown, 2007).

A significant feature of the internationalisation attempt in the last 50 years has been the increasing use of student exchange or 'mobility' programs (Adams, 2007. p.413). These programs offer students opportunities of short term stay in overseas locations, usually as part of joint exchange-styled experiences where students from one institution experience a period of time in a partner institution overseas, the partner institutions usually 'exchanging' students in a synchronous or asynchronous manner.

Student mobility may be for shorter (a few weeks) or longer terms (half year or full year) depending on a range of factors including cost, student support, and synchronicity and similarity of the program or subjects within the program at each institution. During a typical student exchange of this type, students are enrolled in studies at the host institution and study alongside their discipline peers. Credit for studies at the host institution is given in the student's home program, usually commensurate with amount studied. Student mobility programs are often organised at the institutional level but in some instances overseas study or learning experiences may be arranged at the student's instigation, matters pertaining to support and approval of study or credit for the learning experience being managed principally at the level of the course.

Although Australia's more recent historical focus in international study has been particularly about securing overseas students to study at our institutions, Australian domestic student exchange or student mobility programs are 
on the rise in Australia. The sector average of students participating in these opportunities for international exchange is $12.3 \%$ of graduating students, and this has grown from 8.8\% in 2009 (Olsen, 2012). Factors that encourage participation in mobility programs include students' financial context, academic staff interest, institutional support, the quality of international linkages between exchanging institutions, and comparability of program content in the discipline in which students study (Daly, 2011; Knight, 2004).

In spite of the increasing interest in student mobility and 'internationalised' learning opportunities for students, mobility programs can be a financial burden on institutions. With costs of supporting travel grants to outgoing students as well as institutional and service costs to incoming students (e.g., student support, cultural education programs, special accommodation arrangements), the attempt to support international student exchange can be a financially difficult exercise for institutions.

Given that the economics of student mobility programs may be quite different to building international student load, questions inevitably arise about the value of outbound student mobility programs both to the students participating and the institutions supporting it (Forsey, Broomhall, \& Davis, 2012). For student mobility programs to grow and indeed to be justifiable aspects of the educational experience of higher education students, we need to examine our current programs and ask some important questions about what these experiences do, what they could do, and how that can be harnessed to best effect for individual students and their disciplines and the participating institutions themselves.

What do students take away from their experience overseas? How educational is that? Is the overseas experience transformative or simply a matter of translocating the student? What practices or processes used in a mobility program help to make the experience more than just 'educational tourism'? What indeed is the 'take home' learning for students who participate in student mobility programs?

The aim of this research was to attempt to find answers to these questions through an exploration of the views and perceptions of the overseas study experience of a group of Australian early childhood students who participated in a semester length student mobility program in European host institutions. The data reported here based on interviews, reflections, and commentary of those involved in the mobility project offers preliminary answers to such questions.

\section{Student Mobility Project}

The students in this research project were participating in a student mobility project known as the Intercultural Dialogue for Global Leadership and Citzenship in Early Childhood Education Exchange (GLC-EC). It is a student exchange program with the principal aim of giving early childhood undergraduate students and Early Childhood staff the opportunity to go on exchange to a partner university in either the European Union or Australia (Robinson, 2011). There were six universities involved in the Project, three from Australia and three from northern Europe. The Project, led by one of the Australian Universities and one of the European Universities is supported by the Australian Commonwealth Government. In a practical sense, this government support provided for both the program and academic staff development opportunities between the Australian and European institutions. In addition the Australian student costs for relocation and living expenses in the European institution to which they were allocated were also supported. The project has the following stated outcomes:

-Cross-national knowledge production and information exchange;

- Student achievement and engagement in challenging learning, critical reflection on their own and others' perspectives and experimentation with new ideas;

- Academic staff performance in curricula and pedagogical innovation, critical reflection on their practices, systematic documentation of and experimentation with new ideas;

-Administration staff performance in innovative project management; and

- Comparison and consolidation of cross-national transformation in knowledge-in-practice. (Exchange agreement, $29^{\text {th }}$ August, 2011)

The agreement between the participating institutions required that each institution was to receive up to three international students, one from each of the participating overseas consortia. Thus at each of the Australian Universities participating in the program there would be one student from the participating UK institution, one from Denmark and one from Sweden. Each European institution would receive three Australian students, one each from the participating institutions in Queensland, NSW, and Victoria. The Project undertook its first exchange of students in the second half of 2011.

Prospective students were required to apply for the program through a written expression of interest and interview. They needed to have a high grade point average and demonstrate a connection or disposition to the preferred exchange University location. Since the University calendars in Europe and Australia have different start dates, European students would arrive in Australia to begin their studies before the Australian students had departed. In this way, students were able to dialogue and support each other in, or in preparation for, their new environment. Academic and student support staff were available to assist the new arrivals in each University, and the students themselves forged strong support with their exchange peers.

\section{Study Design}

The student participants were currently enrolled in early 
childhood education studies at their home institution—most in their third year of study. There were 18 students annually involved in this exchange project, 3 from each of 3 European Universities and 3 from each of 3 Australian Universities. Over the three years, 54 students participated in this exchange project. After gaining ethics approval, the authors contacted students for this research project through email. Follow up was made by a research assistant. The participants referred to in this study are from the Australian sample (9) in the first year of the project. The participants in this phase of the research were all female students undertaking the third year of a four year early childhood degree.

The aim of this study was to examine the value and benefits obtained from a semester length immersion in higher education and the wider cultural community for Australian teacher education students on exchange in equivalent teacher education programs in selected European sites (University College of Northern Demark, University of Gothenberg, University of East London). The researchers were interested in exploring matters related to the students' experience and reflections on their time as an exchange student and a foreigner living in their respective countries. Most of the data would consist of interview material with some supplementing of the interviews by the authors' and other academics' and early childhood professionals' reflections on the students' experience and academic and professional performance in their host institutions and professional workplaces. Interviews with students undertaking the exchange were to be done on a before, during, and after-the-experience basis with each successive exchange cohort. This type of data collection was suitable to a Grounded Theory approach allowing the researchers 'to investigate phenomena at great and narrow depth' (Jones, Kriflik \& Zanko, 2005). It was a three year project, so it was important to use a method 'readily modifiable as new data come from whatever source - literature, new data, collegial comments, etc.' (Glaser, 2004). The method requires data collection, open categorizing, transcripts, moving toward parsimony through the 'determination of a core category, recycling of earlier steps in terms of the core category, sorting of transcripts, and the write-up of the theory in terms of the picture arrived at through the last step' (Rennie, Phillips \& Quartaro, 1988).

Matters related to the students' learning while abroad particularly with respect to professional practice in their discipline area - were also investigated. Students were initially interviewed individually by the authors using a semi-structured interview approach. Interviews were digitally audio-recorded and then transcribed by a research assistant. Both authors then read through the transcripts independently and noted themes or particular ideas emerging from the transcripts and these were then compared and discussed to clarify and code themes.

During the initial interviews it became apparent that using a free association narrative method allowed the students to tell stories and share experiences that were beyond the questions originally planned (Hollway \& Jefferson, 2009). This resulted in much richer data than might otherwise have been obtained by strictly adhering to the set questions, and uncovered some interesting points noted below. This method was particularly useful given that the students' experiences had often been quite individual or unique and it was considered important to ensure that the relevance of the individual's story was not lost in the interview process.

The interview transcripts were examined and interrogated for meanings related to cultural dissonance, cross-cultural understanding, and reflective practice in education - both as practitioner and student. A key point of discussion will be how these experiences impact on student learning during student exchanges. The next section deals with how students adjusted to their overseas experience, how they benefitted from the mobility experience personally, how it affected them in terms of their degree studies in their discipline area, as well as how their experiences in the field in their host country affected their sense of their profession in their home country and the practice of early childhood education more generally. The findings in this article refer to the data collected from the Australian students on their return from the European exchange, however, the data also reflect, in some instances, informal interviews with students, staff and other observations made by the authors while they were in situ in Denmark and Sweden themselves visiting the host campuses.

\section{The Mobility Experience}

The Australian students from Melbourne, Brisbane and Albury-Wodonga were allocated to one of three European institutions in either England, Denmark, or Sweden. The English institution was located in London and the Swedish institution was located in Gothenburg. The Danish institution was located in the northern province of Denmark (Nordjylland) in a medium-sized town, Hjørring. Hjørring, though much smaller (population less than 25,000) than any of the Australian locations, was surrounded by a rural village system, similar to that found around Albury-Wodonga.

The Australian students engaged in this project typically left for their host nation in the late Australian winter and arrived late summer or early autumn in their home destination, ready to start classes in the autumn/winter semester. Some participants took the opportunity to travel in Europe over the summer before their classes started. These experiences seemed to have helped some of the participants in acclimatizing to their extended European experience as a student at their host institution. It also seemed to help them in adjusting to the cultural dissonance that many reported after the 'reality' of their choice to stay for an extended period in another country had really 'hit home'.

B: I was very overwhelmed when I got to Denmark...I spent about three days going, "Oh my God, what am I doing? I don't know this language. How am I going to live here for three and half months?" 
The sense of being alien for this participant was compounded by people in the host country not always ready to speak in English. 1 Thus when the student would go into the shared kitchen in the student dormitories, local students would occasionally walk out 'because they didn't want to speak English to us'. Not an intentional rejection, perhaps, but nevertheless an alienating experience for the participant and her fellow Australians. However, this participant's reflections about this led her to a decision to challenge her own fears and insecurities in order to make the best of her experience.

B: So I spent about three days saying, 'Oh my God, what am I doing?' and 'This is crazy!' and then I just went, Hold on a second: I've just done a month of travelling [in Europe] and I put myself out there and did a whole lot of things while I was travelling. Like I went skydiving - and I am petrified of heights - but who gets to go skydiving in the Swiss Alps? ... So I thought, All right! Well, if I can do that then I've got to put myself out here in Denmark and that's what I did...I would go into the kitchen and I would make those people talk to me!

But even though being outside the mainstream language could be a barrier to communicating in some instances, it wasn't universally so. Another student reported that their Danish hosts were '...all very inviting...' and that '...you feel welcome and because we were the three Australian students we were treated like royalty.' Indeed, they were 'royal' enough to be invited to meet Prince Frederik and Princess Mary of Denmark when the royal couple made a tour of the campus not long after the Australian students arrived.

The situation for one of the Australian students the authors met and interviewed at the Swedish institution was somewhat different in that, in her case, she was place at an institution with a very significant international student population and accommodated in a large international dormitory where one's nationality did not necessarily deserve greater attention than any one of the many other nationalities present. In some ways this helped alleviate the student's sense of alienation. On the other hand, being confused by other students with US or UK nationals led to some frustration about identity. Nevertheless, meeting up and socialising with the other Australian students helped students accommodate to the cultural differences they were encountering and allowed for an easing of the alienation that sometimes accompanies major domiciliary shifts like this.

The students also experienced differences with respect to the style of education they received at their host institutions. While students reported settling in to the study routine at their host institution there were differences in teaching styles and student behaviour that the Australians noticed. What seemed to be most noticeable at the European institutions was the degree of student autonomy evident in the learning program. In particular, the Australian students were

1 An understandable thing since although many Danes have quite strong English skills, some have only moderate conversational skills learnt at school and, for those living outside the major cities, possibly not maintained since. surprised how self-motivated and committed European students seemed in general. Expectations for group study and dialogue raised the bar significantly for the Australians. As one student reported to the authors, 'In Australia I don't think I ever did all the reading we had to do...Here if you don't, your classmates think very badly of you... If you go for coffee with friends and you don't know what the reading for that week is about you feel ashamed because that's what they're talking about. And they're not reading that in their own language!' It was somewhat of a contrast for all the Australian students since in Australia it was generally seen as 'uncool' to get 'that into' academic study.

\section{Perceptions of Early Childhood Practice}

Because the students in the EU Mobility Project were undertaking an exchange that focussed on developing global understanding of early childhood practice, the students had opportunities - both formal and informal - to engage with practitioners and children and their families in a variety of early childhood workplaces in their host country. For most of the students, the opportunity to work in their chosen field with children of different language and cultural backgrounds was a much anticipated thing. Students expected to see cross-national similarities in practices and approaches to the fundamentals of early childhood education. They expected, in fact, that the similarities outweighed the differences in terms of practice. This was indeed the case for the student who attended early childhood settings in the UK but was not the case for those who attended in the other two locations especially Denmark.

These differences emerge strongly in the statements by $\mathrm{C}$ (exchange in UK) and B (exchange in Denmark):

C: I didn't pick up on anything that was overly different. I was just very surprised as to how similar it was because I just thought that going overseas for the first time, I expected things just to be a bit different but it wasn't... It was just very similar to what I had here.

B: ..in Denmark, it was very much that the children were capable and if they said can I do something, it wasn't, 'Oh no because you might hurt yourself', it was, 'OK, let's go and see what you need to do' and [the children] were supervised to a degree so that [the teachers] knew the child was safe but they never interfered. We interfere all the time [in Australia]. Whether it's because we don't think [the children] are safe or because they're not doing it 'right' or it should be done a different way or they might get something out of it if we do it a different way... I think that's a big thing: just seeing [children] as being capable.

The most striking difference between Australian practices that the students had witnessed in their previous professional experience and - in one case - working life, was the degree of adult control and child-centeredness found in the different locations. Generally speaking, a child-centred approach seemed much more evident in Denmark and Sweden than 
either the UK or Australia.

D [The teachers in Denmark] were so much about the children and if those children wanted to do something they allowed it to happen; they facilitated it in any way they could. Whereas here [in Australia] we restrict the children. A lot of the children don't even come up with the ideas [for activities].

G: ... when I went to Denmark I saw [practice] in a different way: more through letting children do things that ... our society wouldn't let them do - especially in a child care centre sort of situation.

B: We learn here that we should view the children as being capable. What I've seen on placement [in Australia] is not that we view the children as being capable and - given that I've only had a couple of placements - it's not like that is going on everywhere around the country but in Denmark it was very much that the children were [viewed as] capable...

By contrast, one of the students on exchange to the UK reported that after she and the teacher had checked the class folder and discovered the huge range of nationalities in the classroom (20 out of 27 children spoke English as a second language), the teacher seemed to ignore this aspect of the children's lives and just got on with teaching the state mandated curriculum:

Interviewer: ...when you (or the teacher) looked it [the children's nationalities] up and you found that there were a vast number of different cultures in the classroom, did the teaching change in any way? Did that have any impact on what was going on in the classroom?

C: No. As soon as she [had] looked at the folder, she just sat back and taught how she had been teaching the last few weeks.

To some extent these differences in child-centeredness may have derived from the differences in institutional level for the UK children and the Swedish and Danish children. The students in Denmark and Sweden were working in separate prior-to-school settings while the UK setting was a nursery (4-5 year olds) within a primary school setting and in the UK part of the school system. The effects of mandated curriculum would, of course, be more keenly felt in the UK nursery setting. Nevertheless, the lack of attention to language and cultural background in the nursery setting was surprising as the Australian student states:

C: ...if I walked into a classroom here [in Australia] and there were that many different cultures within one classroom, I would expect to see posters reflective of that, photographs, pictures, things about family.

The Nordic countries are renowned for their more liberal progressive approach to Early Childhood education (Einarsdottir \& Wagner, 2006), and the experience of being in an overseas setting, especially for those who went to Denmark and Sweden had a strong impact on the students' sense of comparative practice. This had a strong effect on how the students perceived their Australian Early Childhood practices and this led to a reconsideration of what they felt they would do as a practitioner upon graduation. The students' new feelings about being a practitioner in Australia were not without their misgivings. Students reported that they were ambitious for change but in some cases did not know how to go about producing better practice or doubted themselves as novice practitioners being able to effect change in a workplace.

B: I really want to go into early childhood [education] but I couldn't go into what we have available here... I am very confused now and have no idea about what I want to do because it's not easy especially when I finish I know I am not going to be able to walk into a centre and just say I want to do this, this and this and that's not going to be able to happen...

The power of reflective practice in students' thinking became more evident to the students themselves in this project, and this became the basis for comment in the interviews. It appeared to the researchers that for some students the reflective practice they engaged in led to important reconsideration of their views as early childhood practitioners. The full extent of the impact of reflective practice is not the topic of this article but will be the subject of future publications by the researchers. The value of reflections, especially 'academically driven' reflections is an important aspect of the student's learning in this type of situation. It has the capacity to move the experience of being on student exchange beyond the notion of mere translocation and educational tourism and toward a deeper, more intellectually valuable opportunity for professional growth (Forsey, Broomhall, \& Davis, 2012).

\section{Coming Home}

Students had had strong personal experiences in the host country apart from academic experiences with professional field practice. Apart from the initial sense of alienation people feel when they come to a different culture - mostly the students experienced a warm reception for several months simply on the basis of their novelty or otherness, and this led to strong feelings of attachment to the host country and their new situation.

The students returned to their home institutions and - in some cases workplaces - in Australia which appeared to them to have been in a state of stasis, while they had experienced a range of social, cultural and professional awakenings in their host countries. The students were disappointed that they couldn't easily share this new knowledge with others in Australia. Few people seemed to be able to understand or be interested to discuss with them the importance or significance of their experiences. They have another feeling of cultural dissonance with this return - not as severe as the initial shock of being on their own in another culture for a significant period of time, but alienation nonetheless. They genuinely missed the lives they'd started in the host country and they were now struggling with how to reconcile their previous experience and their own personal growth upon returning to what they thought was a static and somewhat ignorant home culture.

The experience had been a maturing one. They returned 
to Australia with a stronger sense of themselves as young women, but they had also returned to Australia with a much stronger sense of the role of the practitioner in early childhood and were far less tolerant of views put to them by University staff and local practitioners that did not fit with their new ways of thinking. The participants indicated a frustration with their experience of Australian early childhood practice, especially as it related to allowing children freedom to explore and take risks.

B: I have just recently done a birth to two prac and was mortified with what I saw compared to what I know is possible and what I've seen is possible... I cannot see that what is going on in, well, some of the centres out there, as being the best thing for our children...

G: ....at the place I work at they don't let children climb up a little hill or a little something - a step or something and you have to hold their hand and I am [asking] why? It's a thing like the other staff said like, "Oh, you know, they'll fall and hurt themselves"...

D: ...children should be allowed the chance to play with peers and on their own, without constant 'hawking' from adults.

Other concerns emerged about how practitioners were planning for children and what rationale was behind the program implemented in child care centres the participants were either working in or visiting as students back in Australia.

B: I would say, "Well, why are you doing that?" and they [the room leader] could not tell me why they were doing three quarters of the things that they were doing...

\section{Discussion}

As the authors found when they visited the participants in their host country, the students had accommodated well to their social and cultural surroundings. Language differences for the students attending the Danish and Swedish sites seemed to have had little impact on the quality of the educational experiences or, indeed, their daily lives. In fact, most of the students indicated that they would prefer to stay on longer in their host country if visas would permit. Some said that a return trip in the near future to their host country to catch up with newly made friends and acquaintances was very likely. One student had already purchased the air fare.

There is no doubt that the experiences the students had on the mobility project made a difference to them personally, but it was the effect of the experience on their sense of professional practice that was very marked. Though the student attending the UK institution perceived few differences in practices between Australian early school classrooms and the British nursery she was placed in, this was not the case for the students assigned to places in Denmark and Sweden. For these students, there was a significant contrast between what they had experienced on placement and workplaces in Australia and what they had experienced in Scandinavia. Students reported that they were surprised by the differences in approach taken to children in Scandinavia with more evidence in practice of children being trusted, given freedom, and their opinions and values respected (Wagner, 2006). Some of the students also reported that the programs in Scandinavia were more thoughtfully organised around children's interests.

What can we make of this? To some extent, one might put the student reactions down to a kind of 'holiday halo' effect. A not uncommon response to travel where all the recollections of the novelty of the travel experience seem overlaid with a kind of happy, dreamlike, rosy lens. On the other hand, the authors' own observations of the early childhood education programs in Sweden and Denmark in particular tend to confirm many of the students' claims with respect to practice in those locations.

Two things seem to be warranted in helping the students and academics make sense of the apparent differences in practice between host and home country. Firstly, students need to be allowed to articulate their experiences and reactions and have that critically discussed at the home and the host institution. All of the participants spoke to the researchers about the difficulties they faced at home in being able to explain their newfound beliefs to work colleagues, students, workplace supervisors or University lecturers. Of course, some of what the students were claiming was challenging, but rather than shut down the dialogue, we need to facilitate their telling of their own story and have that as the basis of thinking about local home practices and beliefs.

Secondly, we need to encourage students to regularly discuss in their host settings what they see, and how they understand what they are seeing. These reflections need to be moderated by experts from both the host and home sites, so that students can be helped to contextualise what they are seeing and understand it in an appropriate historical, political and cultural framework. We think this might be able to be achieved through processes such as regular blog/chat postings or - if time differences will permit—regular Skype meetings between all the parties involved, not just the students. Also, we think that it would be beneficial to have the European and Australian students participate in moderated online fora while they undertake their overseas placements. As suggested by others (Forsey et al., 2012; Vande Berg, 2007), a systematic approach here to helping students contextualise and interrogate their experience over time is a key component of success in student mobility programs.

Finally, academics and practitioners need to be professionally and culturally robust enough to hear the critiques of our students engaged in foreign practice situations. After all, much of what we know today as best practice in early childhood has come about from sincere questioning of our own practices, often on the back of comparison between ourselves and other national or systemic approaches.

\section{Conclusion}


Although initially Australian students involved in the international mobility program experienced low-level feelings of social and cultural alienation, this was moderated by the degree of cultural integration attempted and achieved. Students were generally surprised by the degree of similarity with the student experience obtained in their foreign locations but Australian students enrolled in Swedish and Danish institutions indicated that higher levels of autonomy and intellectual engagement with the academic program were expected in their host institution than they normally experienced in Australia.

A significant finding for the students engaging in professional experience placements in Sweden and especially in Denmark was that levels of tolerable risk in child care were much higher than those found in Australia. Also approaches that relied on more engagement with the natural world as a fundamental basis for early childhood educational experience were much more evident and expected in these countries than in the students' experience in Australia. Moreover, students were impressed by the child-centred approach taken in the Scandinavian child care centres they visited, with some students commenting on the trust allowed to children and the children's comparative freedom to act and participate (or not) in the program and activities on offer (see Wagner, 2006 for a thoughtful discussion of Nordic ECE practices). This led to a sometimes surprising level of review of their previously held convictions and attitudes to what is considered best practice in early childhood education as well as their view of what constitutes quality learning in teacher education.

For the Australian students participating in this project this has lead to important developments in their sense of their own individual identities and their perception of other cultural practices and attitudes. An important outcome for teacher education students has been their appreciation of normative differences in cultural attitude and practice values with respect to early childhood education. The ideas the students have returned with in some ways appear to challenge 'received wisdom' concerning early childhood practice in Australia.

True internationalisation of the curriculum in higher education requires that students engage in international experiences in ways that lead to student growth in understanding of themselves as global citizens as much as appreciating foreign cultures and practices. Well-designed, longer term student exchanges can result in significant learning for students that challenges not only students' notions of what is 'normal' or given in social and educational matters but leads to a more integrated synthesis about what best or better practices could be.

\section{REFERENCES}

[1] Adams, T. (2007) The development of international education in Australia: A framework for the future. Journal of Studies in International Education, 11, (3/4), 410-420.

[2] Altbach, P. G. \& Knight, J. (2007). The internationalisation of higher education: Motivations and realities. Journal of Studies in International Educational, 11, (3/4), 290-305.

[3] Altbach, P. G. \& Teichler, U. (2001). Internationalisation and exchanges in a globalised university. Journal of Studies in International Education, 5, (1), 5-25.

[4] Daly, A. (2011). Determinants of participating in Australia university student exchange programs. Journal of Research in International Education, 10, (1), 58-70.

[5] Einarsdottir, J. \& Wagner, J. (Eds.) (2006). Nordic childhoods and early education: Philosophy, research, policy, and practice in Denmark, Finland, Iceland, Norway, and Sweden. Greenwich: IAP.

[6] Forsey, M., Broomhall, S., \& Davis, J. (2012). Broadening the mind? Australian student reflections on the experience of overseas study. Journal of Studies in International Education, $16,(2), 128-139$.

[7] Glaser, B. (2004). Remodelling grounded theory. Forum: Qualitative Social Research, 5, (2), 440-454

[8] Healey, N. M. (2008). Is higher education really 'internation alising'? Higher Education, 55, 333-355.

[9] Hollway, W. \& Jefferson, T. (2009). Researching defended subjects with the free association narrative interviewing method. In: H. J. Cook,; S. Bhattacharya, \& A. Hardy, (Eds.), History of the social determinants of health: Global histories, contemporary debates (pp. 296-315). Hyderabad: Orient Black Swan.

[10] Jones, E. (2007). International reflections and culture change. In E. Jones and S. Brown, Internationalising higher education (pp. 25- 41). London: Routledge.

[11] Jones, E. \& Brown, S. (2007) Internationalising higher education. London: Routledge.

[12] Jones, M., Kriflik, G. \& Zanko, M. (2007). Grounded theory: a theoretical and practical application in the Australian Film Industry. Proceedings of QRC05, Johor Bharu, Malaysia, 18 July 2005.

[13] Knight, J. (2004). Internationalization remodelled: Definitio $\mathrm{n}$, approaches and rationale. Journal of Studies in International Education, 8, (1), 5-31.

[14] Olsen, A. (2012). 2012 Research Agenda Australian Universities International Directors Forum. Paper presented at the Australian. International Education Conference, Melbourne, Australia, 5 October, 2012.

[15] Rennie, D., Phillips, J. \& Quartaro, G. (1988). Grounded theory: A promising approach to conceptualization in psychology? Canadian Psychology, 29(2), 139-150.

[16] Robinson, S. (2011). Intercultural Dialogue for Global Leadership: Early Childhood Education. https://sites.google. com/site/aussieandeuecexchange/home Accessed April 18th, 2012.

[17] Vande Berg, M. (2007). Intervening in the learning of U.S. students abroad. Journal of Studies in International Education, 11, 392-399.

[18] Wagner, J. (2006). An outsider's perspective: Childhoods and early education in the Nordic countries. In Einarsdottir, J. \& Wagner, J. (Eds.) Nordic childhoods and early education: Philosophy, research, policy, and practice in Denmark, Finland, Iceland, Norway, and Sweden (pp. 289-306). Greenwich: IAP 